Published in final edited form as:

Neuropharmacology. 2007 June ; 52(8): 1631-1640.

\title{
Presynaptic AMPA and Kainate receptors increase the size of GABAergic terminals and enhance GABA release
}

\author{
Mónica L. Fiszman ${ }^{1}$, Ferenc Erdélyi ${ }^{2}$, Gábor Szabó ${ }^{2}$, and Stefano Vicini ${ }^{1}$ \\ 1 Dept. of Physiology and Biophysics, Georgetown University School of Medicine, Washington, DC \\ 2Laboratory of Molecular Biology and Genetics, Institute of Experimental Medicine, Budapest, Hungary.
}

\section{SUMMARY}

In the developing cerebellum, NMDA receptors promote the maturation of axonal terminals of inhibitory interneurons. We compared the effects of AMPA/kainate receptor agonists in cultured cerebellar cells from GAD65-eGFP mice. Both AMPA and kainate augmented granule cell survival without affecting interneurons. The action of kainate was blocked by an AMPA but not by a NMDA receptor antagonist, suggesting AMPA receptor involvement. AMPA and kainate increased the size of the GABAergic terminals and the action of kainate was insensitive to NMDA blockers. Whole cell recordings in granule neurons revealed that chronic treatments for 5 days with kainate as well as NMDA decreased AMPA receptors expression while interneuronal kainate receptors were depressed by kainate treatment. Acute kainate applications increased mIPSCs frequency in both granule neurons and interneurons and this effect was only partially blocked by an AMPA receptor antagonist. In contrast to what was reported for NMDA, chronic treatments with kainate induced a significant decrease of the basal mIPSCs frequency but increased the acute action of kainate on mIPSCs. Direct recordings from presynaptic GABAergic terminals suggest that AMPA and kainate receptors are present in developing GABAergic terminals and their activation affect the size of GABAergic terminals and spontaneous GABA release.

\section{Keywords}

cerebellum; survival; synapses; interneuron; patch-clamp; eGFP

\section{INTRODUCTION}

The role of ionotropic glutamate receptors on the differentiation of GABAergic interneurons and the maturation of their presynaptic GABAergic terminals is a fundamental question as the central nervous system (CNS) is sculpted by the interplay between excitatory and inhibitory amino acid neurotransmitters.

The availability of transgenic mice that express eGFP driven by the GAD65 promoter (Brager et al., 2003, Lopez-Bendito et al., 2004, Galarreta et al., 2004,Fiszman et al., 2005a) allows direct visualization of GABAergic interneurons and the fine features of their axonal and synaptic processes. We previously reported using these mice that in the developing cerebellum, NMDA receptors promote the maturation of GABAergic basket/stellate interneurons and their

Corresponding Author: Stefano Vicini, Ph.D., Department of Physiology and Biophysics, BSB225, Georgetown University School of Medicine 3900 Reservoir Rd, Washington, DC 20007, Telephone: 202-687-6441 Fax: 202-687-1447 Email: svicin01@ georgetown.edu Publisher's Disclaimer: This is a PDF file of an unedited manuscript that has been accepted for publication. As a service to our customers we are providing this early version of the manuscript. The manuscript will undergo copyediting, typesetting, and review of the resulting proof before it is published in its final citable form. Please note that during the production process errors may be discovered which could affect the content, and all legal disclaimers that apply to the journal pertain. 
axonal terminals, and increase the frequency of spontaneous GABA release (Fiszman et al., 2005a). Cerebellar basket/stellate interneurons reach the molecular layer postnatally, where they are innervated by parallel fibers and establish a complex inhibitory network (Eccles et al., 1967;Palay and Chan-Palay, 1974;Mejia-Gervacio and Marty, 2006). Synaptic efficacy of interneuron innervation changes with development (Pouzat and Hestrin, 1997;Bureau and Mulle, 1998), and exposure to AMPA and NMDA receptors agonists increase the occurrence of miniature spontaneous inhibitory postsynaptic currents (mIPSCs, Bureau and Mulle, 1998; Glitsch and Marty, 1999;Duguid and Smart, 2004;Huang and Bordey, 2004;Fiszman et al., 2005a).

The development of functional inhibitory synapses can be studied in primary cultures of cerebellar cells (Mellor et al., 1998;Ortinski et al., 2004). This culture can be used as a model of cerebellar interneuronal development, which allows direct measurements of synaptic function.

There is anatomical evidence for the presence of AMPA receptor subunits in cerebellar molecular layer interneurons (Petralia and Wenthold, 1992;Baude, et al., 1994;Petralia et al., 1997). Furthermore, stellate and basket cells show the selective expression of the GluR7 subunit gene of the kainate receptor family (Bettler et al., 1992;Wisden and Seeburg, 1993).

The expression of these glutamate receptors in basket/stellate cells in primary culture has not been investigated because of the difficulty to identify interneurons in cerebellar cultures. Using primary cultures of cerebellar neurons derived from GFP-GAD65 transgenic mice that allow the identification of basket/stellate cells, we provide functional evidence that both kainate and AMPA receptors are present in these neurons and that they regulate GABAergic inhibitory neurotransmission. This work has been presented in form of an abstract (Fiszman et al., 2005b).

\section{MATERIALS and METHODS}

\section{Cerebellar cell cultures, survival studies and imaging}

Primary cultures of mouse cerebellum were prepared from postnatal day 6-8 GAD65-EGFP mice as in Fiszman et al. (2005a). Mouse pups were sacrificed by decapitation in agreement with the guidelines of the Georgetown University Animal Care and Use Committee in accordance with the National Institutes of Health guide for the care and use of Laboratory animals (NIH Publications No. 8023, revised 1978). All efforts were made to minimize animal suffering, to reduce the number of animals used. Briefly, cerebella were dissociated with trypsin on glass coverslips coated with poly-L-lysine in $35 \mathrm{~mm}$ dishes. The cells were cultured in Basal Eagle's medium supplemented with $10 \%$ fetal bovine serum, $2 \mathrm{mM}$ glutamine, $20 \mu \mathrm{g} / \mathrm{ml}$ gentamycin (all from Invitrogen Corporation Carlsbad, CA), $0.1 \mathrm{mg} / \mathrm{ml}$ transferrin and 0.025 $\mathrm{mg} / \mathrm{ml}$ insulin (Sigma-Aldrich-RBI, Mo). Cells were maintained at $37^{\circ} \mathrm{C}$ in $5 \% \mathrm{CO}_{2}$ and treatments with kainate, NMDA, MK801, cyclothiazide, concanavalin A (Sigma-AldrichRBI), (S)-AMPA, GYKI52466 (Tocris, UK), were performed at DIV2 and kept for 5 days. GYKI52466 and/or MK801 were added one hour before the addition of agonists.

Live cultured neurons were fixed by incubation with $4 \%$ paraformaldehyde, $4 \%$ sucrose in PBS for $10 \mathrm{~min}$ and washed 3 times in PBS. Survival was assessed from the total number of neurons counted in at least 10 fields of $400 \times 500 \mu \mathrm{m}$ per cover slip and is expressed as \% control. Average density of cells ranged between 50 and 200 cells per field.

Neurons were imaged as in Fiszman et al., (2005a). Briefly, digital images were acquired with a CCD digital camera with a $1360 \times 1024$ pixel array and were analyzed with MetaMorph (Universal Imaging, Downingtown, PA). The number and size of eGFP containing boutons 
were determined in thresholded and randomly selected, $10 \mu \mathrm{m}$ axonal segments. At least 30 segments were analyzed in each experimental group from 6 separate cultures unless otherwise stated. In all cases statistical comparisons were done using a two-tailed Student's t test assuming homogeneity of variances of the samples with Bonferroni corrections. Data values are expressed as mean \pm standard error of the mean.

\section{Electrophysiology}

All recordings were performed at room temperature $\left(24-26^{\circ} \mathrm{C}\right)$ from neurons maintained for 6 to 8 DIV. Extracellular solution contained (in $\mathrm{mM}$ ): $\mathrm{NaCl}$ (145), $\mathrm{KCl}$ (5), $\mathrm{MgCl}_{2}$ (1), $\mathrm{CaCl}_{2}$ (1), HEPES (5), glucose (5), sucrose (15), phenol red (0.25mg/l) and D-serine $(10 \mu \mathrm{M})($ all from Sigma) adjusted to $\mathrm{pH} 7.4$ with $\mathrm{NaOH}$. Electrodes were filled with recording solution containing (in mM): $\mathrm{KCl}$ (145), HEPES (10), ATPMg (5), GTPNa (0.2), and BAPTA (10), adjusted to $\mathrm{pH} 7.2$ with $\mathrm{KOH}$. Pipette resistance was 5-7 M 2 . Whole cell voltage-clamp recordings were made at $-60 \mathrm{mV}$ with an Axopatch-1D amplifier (Axon Instruments, Union City,CA) and access resistance was monitored throughout the recordings. Current density was determined from capacitance calculated from a transient current response to a hyperpolarizing $10 \mathrm{mV}$ pulse. Currents were filtered at $1 \mathrm{kHz}$ with an 8-pole low-pass Bessel filter, digitized at $5 \mathrm{kHz}$ using an IBM-compatible microcomputer equipped with Digidata 1322A data acquisition board and pCLAMP9 software (both from Axon Instruments). Off-line data analysis, curve fitting, and figure preparation were performed with Clampfit 9 software. Solution was exchanged locally with a Y tube (Murase et al., 1989). mIPSCs were isolated by application of $0.5 \mu \mathrm{M}$ tetrodotoxin (TTX, Alomone Labs, Israel). Infrequent AMPA-mediated mEPSCs were easily identified by the very rapid decay $(<2 \mathrm{~ms})$ and excluded from the analysis. mIPSC averages were based on at least 50 events in each cell studied. mIPSCs were studied in a time interval that ranged from 10 minutes to one hour after each coverslip with neurons was placed on the recording setup. Once the whole cell recording was established, we waited for mIPSC frequency to become stable to collect data, typically 30-60 seconds. Concanavalin A (Con A) was locally preapplied at a concentration of $20 \mu \mathrm{M}$ for at least 5 minutes. All data are expressed as mean \pm standard error of the mean, unless otherwise indicated; $p$ values represent the results of two-tailed Student's t tests with Bonferroni corrections.

\section{RESULTS}

\section{AMPA and Kainate increase survival of CGCs and alter the morphology of GABAergic interneurons in cerebellar cultures}

We compared the effects of treatments with AMPA and kainate with those of NMDA on the survival and morphological differentiation of cerebellar neurons from GAD65-eGFP mice in primary neuronal cultures. In these cultures the majority of neurons are granule cells and about 3\%of the neurons are GFP positive GABAergic interneurons (Fig. 1, Fiszman et al., 2005a). Qualitative observations of fluorescence images indicate substantial changes in the morphology of GABAergic interneurons with kainate (Fig. 1). Treatment with increasing doses of kainate or AMPA enhanced survival of granule cells (Fig. 2A\&B). The effects of both excitatory amino acid receptor agonists were inhibited by the selective AMPA receptor antagonist GYKI52466. Furthermore, the kainate-induced survival was not affected by the NMDA receptor antagonist MK-801 (Fig.2A), suggesting that this was due to a direct activation of an AMPA/Kainate receptor and not due to kainate induced glutamate release acting on NMDA receptors. Additionally, the NMDA -induced survival was not affected by GYKI52466. Lastly, the AMPA-induced increase in CGC survival was not potentiated by cyclothiazide. These results taken together suggest that both AMPA and NMDA receptors can mediate neurotrophic effects on cerebellar granule neurons. Cerebellar granule neurons in culture also express kainate receptors (Pemberton et al., 1998). Incubation with lectins, including Con A, has been shown to eliminate desensitization of native kainate receptors 
(Mayer and Vyklicky, 1989). Thus we tested the effect of Con A on survival. At two concentrations tested $(1$ and $10 \mu \mathrm{M})$, inclusion of ConA in the growth medium, induced a complete neuronal death within 24 hours of treatment.

We previously reported that NMDA did not increase the proportion of GABAergic interneurons (Fiszman et al., 2005a) and here we provide evidences that both kainate and AMPA did not change the percent of GABAergic interneurons (Fig. 2C\&D). The highest doses of both agonists decreased the percent of GABAergic interneurons, suggesting a neurotoxic effect.

Treatment with both AMPA or kainate induces a pronounced change in the size of axonal boutons (Fig. 1 and Fig. 3 A,B) which as reported for NMDA began 18-24 hours after treatment and is fully established at 72 hours postreatment (Fiszman et al., 2005a). As we previously reported, these varicosities were likely presynaptic GABAergic terminals as they immunostained for GAD65, synapsin 1 and VAMP2 (Fiszman et al., 2005a). We quantified the extent of presynaptic boutons enlargement in axons of cerebellar GABAergic interneurons in primary culture (Fig. 3). Both kainate and AMPA actions were dose-dependent and similar to the effect of NMDA (Fig. 3). In contrast to the effect on CGCs survival, the varicosities enlargement induced by kainate was inhibited significantly but not completely by two concentrations of GYKI52466, 25 and $50 \mu \mathrm{M}$ (Fig 3A). This is expected, as kainate acts on both kainate and AMPA receptors and GYKI is a selective AMPA receptor antagonist. This effect of kainate was also not affected by the NMDA receptor antagonist MK-801 (Fig 3A). As expected, AMPA action was blocked by GYKI52466 and potentiated by cyclothiazide (Fig 3B). Our results taken together suggest that both AMPA and kainate receptors produce axonal varicosities enlargement. Next, we sought to establish the functional relevance of these changes.

\section{Kainate induces whole-cell currents and increases spontaneous synaptic release from GABAergic interneurons in cerebellar cultures}

We investigated the occurrence of functional AMPA and kainate receptors in cultured cerebellar neurons by recording whole-cell currents with the application of two concentrations of kainate and the selective AMPA receptor antagonist GYKI52466 (Fig 4). As shown in Fig. $4 \mathrm{~A}$ application of $20 \mu \mathrm{M}$ kainate elicited robust inward currents in both granule neurons and interneurons. The size of the kainate response was however much larger in interneurons. This increase of current was not simply due to the larger membrane area of the GABAergic neurons, as the whole-cell current density, normalized by whole-cell capacitance, was also significantly larger in interneurons (Fig.4B\&4C). We further investigated the occurrence of kainate receptors by performing whole cell recordings with low concentration of kainate, by using an AMPA receptor blocker or by removing desensitization with pretreatments with ConA. As shown in Fig. 4B\&C, application of $2 \mu \mathrm{M}$ kainate, only elicited small whole cell current in both neuronal populations. These currents were significantly potentiated in granule neurons but not in interneurons by ConA. Co-application of $20 \mu \mathrm{M}$ kainate with $50 \mu \mathrm{M}$ GYKI52466 induced a potent inhibition of the current elicited by $20 \mu \mathrm{M}$ kainate alone, but a significant residual current was observed (Fig 4B\&4C). These data taken together suggest that while the majority of receptors in both cell types were AMPA receptors, kainate receptors were also present, as previously shown in granule neurons (Pemberton et al., 1998). We also investigated if treating the cerebellar cultures beginning at DIV2 for 5 days with either $20 \mu \mathrm{M}$ kainate or $100 \mu \mathrm{M}$ NMDA altered the receptor expression profile. As seen in Fig.4B both kainate and NMDA treatments decreased the current density measured with $20 \mu \mathrm{M}$ kainate in cerebellar granule neurons. In contrast, kainate current density was significantly reduced in GABAergic interneurons by kainate but not by NMDA treatments (Fig. 4C). In these neurons we also measured consistent whole cell currents elicited by NMDA in the presence of physiological 
$\mathrm{Mg}^{2+}$ (Fig 4C). The NMDA current density was significantly decreased by both kainate and NMDA treatments (Fig 4B \& 4C). NMDA treatments significantly altered the portion of kainate receptors in granule neurons and in interneurons as seen by the response to $2 \mu \mathrm{M}$ kainate, by removing desensitization with pretreatments with ConA or by assessing the residual response to $20 \mu \mathrm{M}$ kainate and GYKI52466 (Fig 4B \& 4C). However, kainate treatment significantly decreased kainate receptors in interneurons but not in granule neurons (Fig 4B \& $4 \mathrm{C})$.

We then investigated spontaneous synaptic release from GABAergic terminals by measuring miniature inhibitory postsynaptic currents (mIPSCs) from cerebellar granule neurons voltageclamped at $-60 \mathrm{mV}$ and with symmetrical $\mathrm{Cl}^{-}$solution as in Fiszman et al., (2005a). The frequency of mIPSCs, observed as inward currents (Fig. 5A), was suddenly and persistently increased by acute application of $20 \mu \mathrm{M}$ kainate. As previously shown, $30 \mu \mathrm{M}$ NMDA caused a similar effect (Fiszman et al., 2005a). The changes in mIPSC frequency were not accompanied by changes in amplitude or decay kinetics (not shown). Fig.5B illustrates the summary results on mIPSCs frequency in control granule neurons and neurons treated chronically for 5 days with $20 \mu \mathrm{M}$ kainate or $100 \mu \mathrm{M}$ NMDA. Kainate pretreatment not only failed to mimic the mIPSCs frequency increase we previously reported with chronic NMDA treatments but it also induced a significant decrease. Co-application of GYKI52466 antagonized this effect in a subset of granule cells as seen in the two examples in Fig. 5A. Fig $5 \mathrm{C}$ reports the percent of cells in the distinct chronic treatments that display significant antagonism by GYKI52466.

Fig. 5D reports the summary data on the mIPSCs frequency increases with acute application of $20 \mu \mathrm{M}$ kainate compared to the effect of $30 \mu \mathrm{M}$ NMDA in all cells studied. These data are also shown for granule neurons in cultures at DIV7-8 chronically treated for 5 days with 20 $\mu \mathrm{M}$ kainate or $100 \mu \mathrm{M}$ NMDA. As seen in this panel, $20 \mu \mathrm{M}$ kainate similarly to $30 \mu \mathrm{M}$ NMDA significantly increased mIPSCs frequency over baseline frequency (in Fig. 5B). The increase in mIPSC frequency with $30 \mu \mathrm{M}$ NMDA was not significantly different from that observed with $20 \mu \mathrm{M}$ kainate. The increase in the number of cells that were GYKI52466 responders in Fig 5C (\% GYKI responders), together with the increase in the response to $20 \mu \mathrm{M}$ kainate with chronic kainate treatment suggest an increase of presynaptic AMPA receptors. In contrast, when mIPSCs were recorded from granule cells grown in the presence of NMDA, both kainate and NMDA became ineffective to increase mIPSC frequency. Fig. 5E reports the summary data only from cells where $20 \mu \mathrm{M}$ GYKI52466 did not antagonize the mIPSC frequency increases induced by $20 \mu \mathrm{M}$ kainate (GYKI non responders). In these cells, acute application of $2 \mu \mathrm{M}$ kainate is compared to that of $2 \mu \mathrm{M}$ kainate after pretreatment with ConA and of 20 $\mu \mathrm{M}$ kainate combined with $50 \mu \mathrm{M}$ GYKI52466. These data are also shown for granule neurons chronically treated for 5 days at DIV2 with $20 \mu \mathrm{M}$ kainate. The increase of mIPSC frequency seen with $2 \mu \mathrm{M}$ kainate was significantly potentiated by ConA pretreatment suggesting the presence of presynaptic kainate receptors in GYKI "non responder" cells (Fig. 5C and 5E). Chronic kainate treatment failed to affect the response to $2 \mu \mathrm{M}$ kainate, the potentiation of the response to $2 \mu \mathrm{M}$ kainate by ConA, or the residual mIPSC frequency increase seen with 20 $\mu \mathrm{M}$ kainate and $50 \mu \mathrm{M} \mathrm{GYKI}$ (Fig 5E). This suggests that the abundance of presynaptic kainate receptor is not affected by chronic kainate treatment. In contrast, NMDA chronic treatment, down regulated the occurrence of presynaptic kainate receptors as seen in the large increase in $\%$ GYKI responders (Fig 5C). These results taken together, strongly suggest that AMPA and kainate receptors are unevenly distributed in cerebellar granule cell terminals and their expression can be differentially regulated by chronic treatments. 


\section{Kainate currents from presynaptic terminals}

As we previously reported (Fiszman et al., 2005a), it is possible to record directly from enlarged 'presynaptic' boutons in primary cultures of cerebellar neurons from GAD65-eGFP mice. Patch-clamp recordings from varicosities such as those illustrated in Fig. 6A, allow to measure currents elicited by direct application of $20 \mu \mathrm{M}$ kainate as in Fig. 6B. Although both NMDA and kainate treatments made the varicosities larger and therefore easier to record from, we could also perform recordings from the largest varicosities seen in vehicle treated cells. Strikingly, the extent of inhibition by $50 \mu \mathrm{M}$ GYKI52466 was quite different from terminal to terminal and depended upon the chronic treatment of the culture. As shown in Fig. 6C, the summary data on the whole terminal current recorded from cells treated with kainate was not significantly larger than that in cells treated with vehicle. In contrast, the whole terminal current was significantly smaller in cells treated with NMDA. In addition, the inhibition by $50 \mu \mathrm{M}$ GYKI52466 was significant only in cells treated with kainate. Although we cannot exclude that the currents we recorded from the terminals were at least in part generated in the cell body of the GABAergic interneuron and propagated to the varicosity, our data support a heterogeneous distribution of presynaptic kainate and AMPA receptors. This presynaptic receptor distribution appears to be altered by chronic treatments.

\section{DISCUSSION}

In slices of developing cerebellar basket/stellate cells, kainate increases mIPSCs frequency by acting on presynaptic AMPA receptors possibly located on GABAergic terminals (Bureau and Mulle, 1998). We extend these data to basket/stellate cells in primary cultures demonstrating the occurrence of both presynaptic AMPA and kainate receptors. Thus, we propose a morphological correlate to functional changes in release probability, along the line to what we previously have shown with NMDA receptors (Fiszman et al., 2005a).

It was previously found that AMPA at a high concentration $(500 \mu \mathrm{M})$ increased granule cells survival (Wu et al., 2004). Our data support these findings but also show that much lower concentrations of either AMPA or kainate are required for this action and that AMPA or NMDA receptors can independently mediate the increased survival of cerebellar granule neurons. It is likely that the AMPA receptors can also support the required calcium entry needed for the neurotrophic effect. Indeed, whole cell recordings from CGCs support the notion that the majority of the current elicited by kainate is through AMPA receptors and most likely these receptor are permeable to calcium as labelling with a GluR2-specific antibody has revealed a virtual absence of the GluR2 subunit in these cells in vivo (Petralia et al., 1997). As previously reported (Pemberton et al., 1998), cerebellar granule neurons in culture express low levels of kainate receptors. We support these findings but also observed that in contrast to simulation of AMPA and NMDA receptors, the removal of kainate receptor desensitization with ConA induces neuronal death. While further studies are necessary to investigate the underlying mechanism leading to cell death, it is possible that the amount of $\mathrm{Ca}^{2+}$ influx through kainate receptors reaches neurotoxic levels.

In contrast to NMDA treatments (Fiszman et al., 2005a), AMPA and kainate do not increase the proportion of GABAergic interneurons in the culture but do not decrease survival either. However, as kainate at $50 \mu \mathrm{M}$ has been shown to be toxic for interneurons (Drejer and Schousboe, 1989;Damgaard et al., 1996), one should consider the possibility that a survival promoting effect of kainate at the doses we used could be masked by the neurotoxic action.

We have previously shown that NMDA increases the size of axonal varicosities of GABAergic interneurons. Here we have observed that both kainate and AMPA share this effect with NMDA. These varicosities are GABAergic terminals as seen with both immunoctyochemical and electrophysiological studies (Fiszman et al., 2005). Kainate induced varicosities 
enlargement was partially blocked by selective antagonists of NMDA or AMPA receptors. This suggests that all three receptors, AMPA, kainate and NMDA, can mediate morphological changes in GABAergic axons. As cyclothiazide enhances the effect of low concentration of AMPA on terminal differentiation but not on neuronal survival, it is possible that the AMPA receptors mediating these effects are distinct. Indeed, it has been reported that the mRNA for AMPA receptor splice forms with distinct sensitivity to cyclothiazide differ between culture conditions and development (Longone et al., 1998).

In our previous study (Fiszman et al., 2005a), the effects on GABAergic bouton size of endogenously released glutamate stimulated by high extracellular potassium concentrations were completely blocked by NMDA antagonists. Although this may suggests that endogenous glutamate released in this conditions act on NMDA rather than AMPA and kainate receptors to affect presynaptic varicosities, it is likely that the action of MK801 in high potassium can also indirectly affect AMPA/kainate receptors. In fact endogenous glutamate released by depolarizing potassium concentrations has an effect on excitability of the culture network via all NMDA receptors inducing further glutamate release and activation of both AMPA/kainate and NMDA receptor on presynaptic terminal. Thus blocking NMDA receptors will decrease the amount of glutamate elicited by high potassium and AMPA/kainate receptor activation. Nevertheless, the fact that presynaptic AMPA/kainate receptor can share the action on presynaptic terminal of NMDA receptors opens the question of their physiological role in regulating varicosities. The selective effect of endogenous glutamate on AMPA/kainate receptors may occur with particular synaptic activation and it may relate to the properties of glutamate diffusion in the intact cerebellum.

Whole cell recordings show that mIPSCs frequency can be increased by acute application of kainate. This effect is similar to that of NMDA and is variably blocked by the AMPA receptor blocker. This further supports the hypothesis that all three receptors are present in presynaptic terminals.

In our previous work we demonstrated that the enlargement of the terminal is paralleled by an increase of the basal mISPC frequency with NMDA chronic treatment. In contrast in kainate treated cells, the enlargement of the terminals was accompanied by a decrease of mIPSCs frequency. Furthermore, in cells treated with NMDA the acute effect of NMDA application was depressed while the opposite was seen in cells treated with kainate. Thus, it seems that the regulation of spontaneous release is not directly related to the terminal size but it depends on the basal level of spontaneous release. Further studies will have to relate the changes in intracellular calcium and calcium release mechanisms occurring with the different excitatory amino acids. We believe that the larger size of the terminal corresponds to increased vesicle availability that allows for more frequent release when presynaptic AMPA/kainate receptors are activated. Thus, we propose that while presynaptic NMDA receptors establish a constitutive vesicle release, AMPA/kainate receptor allow for changes in release that can be triggered only by direct presynaptic activation.

Whole cell current recordings suggest that the majority of receptors activated by kainate in both cerebellar neurons are AMPA receptors, although a small portion of kainate receptors are also present as previously shown (Penderton et al., 1998). The presence of kainate and AMPA receptors is heterogeneous among cells. Direct recordings supports heterogeneity in the presence of kainate versus AMPA receptors also in presynaptic terminals of cerebellar GABAergic interneurons. Chronic treatments with the distinct agonists can regulate the proportion of excitatory amino acid receptors. In vehicle treated cultures, the presence of kainate receptor was quite consistent while in kainate treated cells the proportion of AMPA receptors was upregulated. NMDA treatment downregulated both receptors. It remains to be 
seen how the selective activation of presynaptic kainate receptor will affect the relative receptor expression.

Interestingly, Bureau and Mulle (1998) reported a developmental decrease in presynaptic activation of GABAergic terminals in stellate cells by domoate, an AMPA/kainate receptors agonist. One proposed explanation for this phenomenon was the possible migration of AMPA receptors from synaptic terminals to somatodendritic location with age in vivo. Our data suggest that presynaptic kainate and NMDA receptor may act as antagonistic regulators of this effect.

Our data illustrate that the current produced in presynaptic terminals by acute kainate application is of similar amplitude in terminals chronically treated with vehicle or kainate, while the increase in mIPSC frequency with kainate is increased in cells chronically treated with kainate. As chronic treatments with kainate decrease significantly basal mIPSCs frequency, it is possible that adaptive changes in intracellular presynaptic calcium and/or release machinery underlie the distinct actions of kainate.

A key question in our finding is why glutamate, acting as the endogenous activator of these presynaptic receptors in GABAergic terminal, requires the activation of the distinct receptor subtypes. In addition it remains to be established what is the effect of activation of these receptors on the evoked synaptic release. Perhaps the regulation of GABAergic release requires multiple regulatory mechanisms to properly shape the relative synaptic strengths via presynaptic neurotransmitter release.

\section{ACKNOWLEDGMENTS}

This work was supported by NIH grant NS047700 to SV and OBFB-00498/2002 to GS. We are grateful to Dr John Partridge for editing style and grammar of our paper

\section{References}

Baude A, Molnar E, Latawiec D, McIlhinney RA, Somogyi P. Synaptic and nonsynaptic localization of the GluR1 subunit of the AMPA-type excitatory amino acid receptor in the rat cerebellum. Journal of Neuroscience 1994;14:2830-2843. [PubMed: 8182442]

Bettler B, Egebjerg J, Sharma G, Pecht G, Hermans-Borgmeyer I, Moll C, Stevens CF, Heinemann S. Cloning of a putative glutamate receptor: a low affinity kainate-binding subunit. Neuron 1992;8:257265. [PubMed: 1371217]

Brager DH, Luther PW, Erdelyi F, Szabo G, Alger BE. Regulation of exocytosis from single visualized GABAergic boutons in hippocampal slices. Journal of Neuroscience 2003;23:10475-10486. [PubMed: 14627631]

Bureau I, Mulle C. Potentiation of GABAergic synaptic transmission by AMPA receptors in mouse cerebellar stellate cells: changes during development. Journal of Physiology (London) 1998;509:817831. [PubMed: 9596802]

Damgaard I, Trenkner E, Sturman JA, Schousboe A. Effect of $\mathrm{K}^{+}$- and kainate-mediated depolarization on survival and functional maturation of GABAergic and glutamatergic neurons in cultures of dissociated mouse cerebellum. Neurochemical Research 1996;21:267-275. [PubMed: 9182252]

Drejer J, Schousboe A. Selection of a pure cerebellar granule cell culture by kainate treatment. Neurochemical Research 1989;14:751-754. [PubMed: 2812251]

Duguid IC, Smart TG. Retrograde activation of presynaptic NMDA receptors enhances GABA release at cerebellar interneuron-Purkinje cell synapses. Nature Neuroscience 2004;7:525-533.

Eccles, JC.; Ito, M.; Szentágothai, J. The cerebellum as a neuronal machine. Springer; New York: 1967.

Fiszman ML, Barberis A, Lu C, Fu Z, Erdelyi F, Szabo G, Vicini S. NMDA receptors increase the size of GABAergic terminals and enhance GABA release. Journal of Neuroscience 2005a;25:2024-2031. [PubMed: 15728842] 
Fiszman, ML.; Erdelyi, F.; Szabo, G.; Vicini, S. Presynaptic AMPA and Kainate receptors increase the size of GABAergic terminals and enhance GABA release Program No. 843.5. Society for Neuroscience; Washington, DC: 2005b. Abstract Viewer/Itinerary PlannerOnline

Galarreta M, Erdelyi F, Szabo G, Hestrin S. Electrical coupling among irregular-spiking GABAergic interneurons expressing cannabinoid receptors. Journal of Neuroscience 2004;24:9770-9778. [PubMed: 15525762]

Glitsch M, Marty A. Presynaptic effects of NMDA in cerebellar Purkinje cells and interneurons. Journal of Neuroscience 1999;19:511-519. [PubMed: 9880571]

Huang H, Bordey A. Glial glutamate transporters limit spillover activation of presynaptic NMDA receptors and influence synaptic inhibition of Purkinje neurons. Journal of Neuroscience 2004;24:5659-5669. [PubMed: 15215288]

Lopez-Bendito G, Lujan R, Shigemoto R, Ganter P, Paulsen O, Molnar Z. Blockade of GABA(B) receptors alters the tangential migration of cortical neurons. Cerebral Cortex 2003;13:932-942. [PubMed: 12902392]

Longone P, Impagnatiello F, Mienville JM, Costa E, Guidotti A. Changes in AMPA receptor-spliced variant expression and shift in AMPA receptor spontaneous desensitization pharmacology during cerebellar granule cell maturation in vitro. Journal of Molecular Neuroscience 1998;11:23-41. [PubMed: 9826784]

Mayer ML, Vyklicky L Jr. Concanavalin A selectively reduces desensitization of mammalian neuronal quisqualate receptors. Proceedings of the National Acadamey of Science USA 1989;86:1411-1415.

Mejia-Gervacio S, Marty A. Control of interneurone firing pattern by axonal autoreceptors in the juvenile rat cerebellum. Journal of Physiology (London) 2006;571:43-55. [PubMed: 16339174]

Mellor JR, Merlo D, Jones A, Wisden W, Randall AD. Mouse cerebellar granule cell differentiation: electrical activity regulates the GABAA receptor alpha 6 subunit gene. Journal of Neuroscience 1998;18:2822-2833. [PubMed: 9525999]

Murase K, Ryu PD, Randic M. Excitatory and inhibitory amino acids and peptide-induced responses in acutely isolated rat spinal dorsal horn neurons. Neuroscience Letters 1989;103:56-63. [PubMed: 2476693]

Ortinski PI, Lu C, Takagaki K, Fu Z, Vicini S. Expression of distinct alpha subunits of GABAA receptor regulates inhibitory synaptic strength. Journal of Neurophysiology 2004;92:1718-17127. [PubMed: 15102896]

Palay, SL.; Chan-Palay, V. Cerebellar cortex: cytology and organization. Springer; New York: 1974.

Pemberton KE, Belcher SM, Ripellino JA, Howe JR. High-affinity kainate-type ion channels in rat cerebellar granule cells. Journal of Physiology (London) 1998;510:401-420. [PubMed: 9705992]

Petralia RS, Wenthold RJ. Light and electron immunocytochemical localization of AMPA-selective glutamate receptors in the rat brain. Journal of Comparative Neurology 1992;318:329-354. [PubMed: 1374769]

Petralia RS, Wang YX, Mayat E, Wenthold RJ. Glutamate receptor subunit 2-selective antibody shows a differential distribution of calcium-impermeable AMPA receptors among populations of neurons. Journal of Comparative Neurology 1997;385:456-476. [PubMed: 9300771]

Pouzat C, Hestrin S. Developmental regulation of basket/stellate cell-->Purkinje cell synapses in the cerebellum. Journal of Neuroscience 1997;17:9104-9112. [PubMed: 9364057]

Wisden W, Seeburg PH. A complex mosaic of high-affinity kainate receptors in rat brain. Journal of Neuroscience 1993;13:3582-3598. [PubMed: 8393486]

Wu X, Zhu D, Jiang X, Okagaki P, Mearow K, Zhu G, McCall S, Banaudha K, Lipsky RH, Marini AM. AMPA protects cultured neurons against glutamate excitotoxicity through a phosphatidylinositol 3kinase-dependent activation in extracellular signal-regulated kinase to upregulate BDNF gene expression. Journal of Neurochemistry 2004;90:807-818. [PubMed: 15287886] 


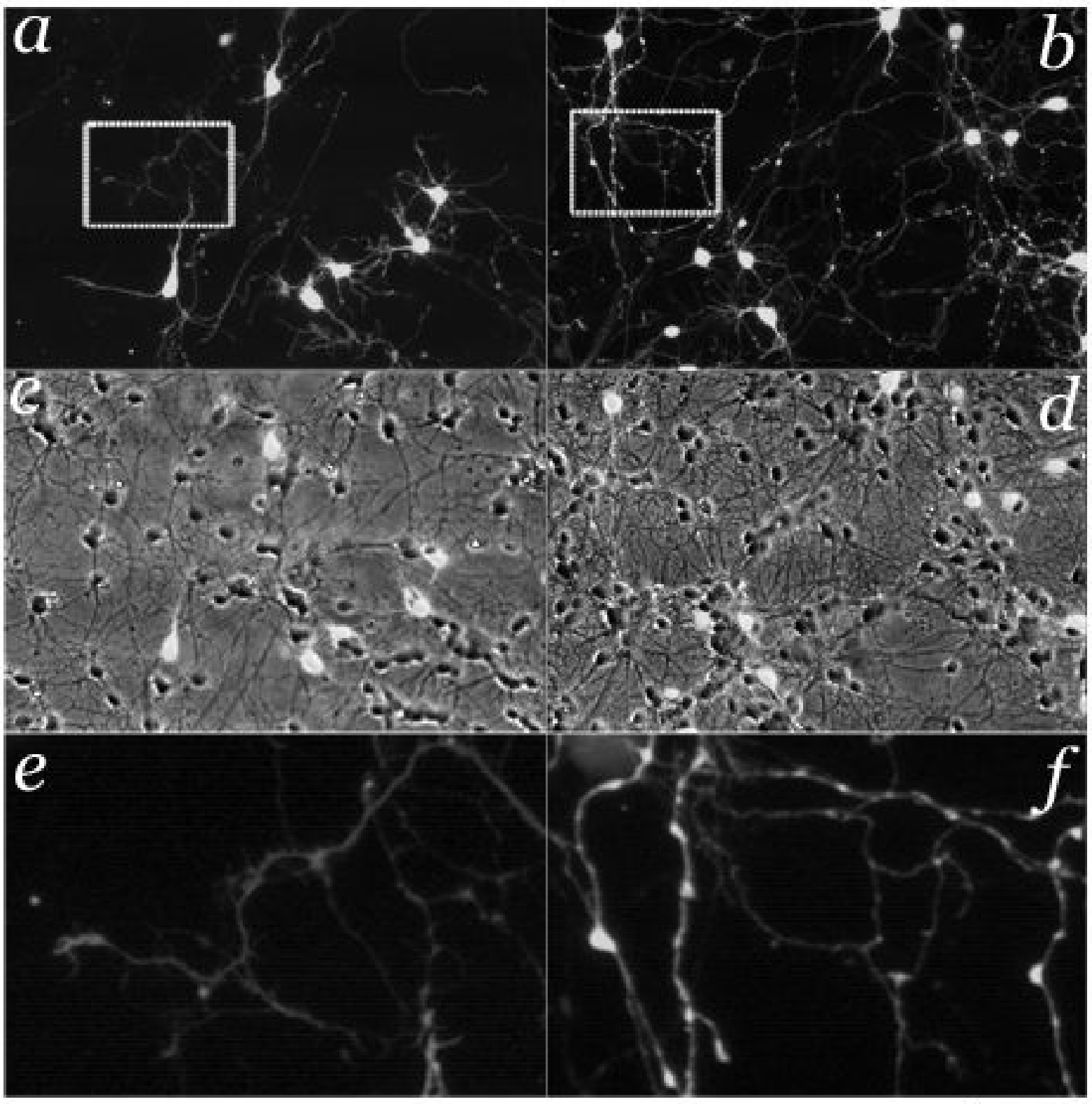

Fig1. Cerebellar neurons in primary cultures from GAD-65 expressing mice

Cerebellar cultures at DIV7 grown for 5 days in the absence (left) or the presence of $20 \mu \mathrm{M}$ kainate (right). Qualitative observations of fluorescent images indicate substantial changes induced by kainate treatment: increased survival of granule neurons and enhanced size of the GABAergic axonal varicosities. In panels $\boldsymbol{c}$ and $\boldsymbol{d}$ the fluorescence microphotographs in $\boldsymbol{a}$ and $\boldsymbol{b}$ are overlapped to phase contrast ones to illustrate the density of granule neurons and GABAergic interneurons. Panels $\boldsymbol{e}$ and $\boldsymbol{f}$ illustrate a magnified sections of panels $\boldsymbol{a}$ and $\boldsymbol{b}$ that better show GABAergic axonal branches and presynaptic varicosities. Calibration bar $30 \mu \mathrm{m}$ and $6 \mu \mathrm{m}$ for the insets. 

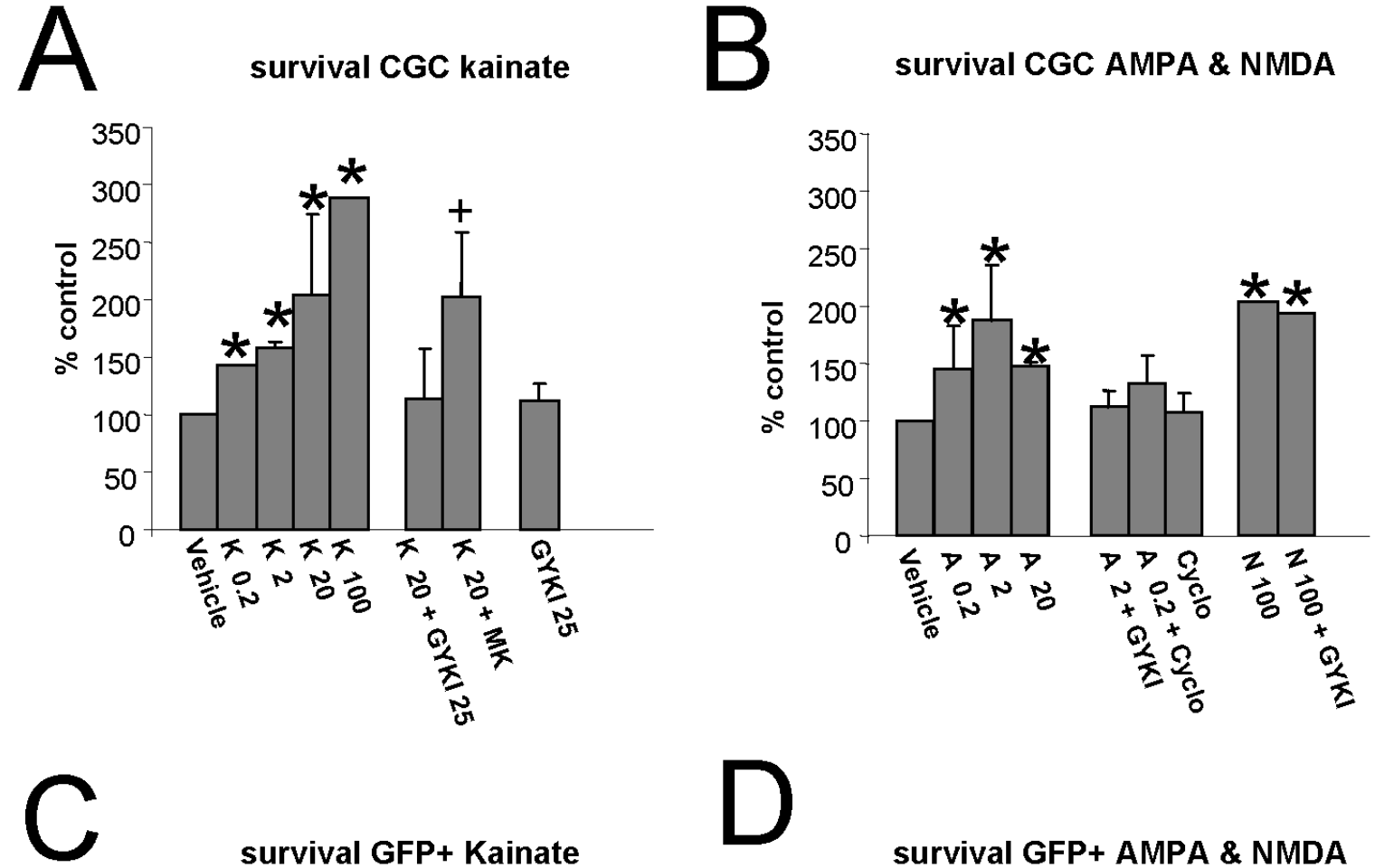

survival GFP+ Kainate

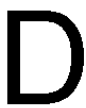

survival GFP+ AMPA \& NMDA
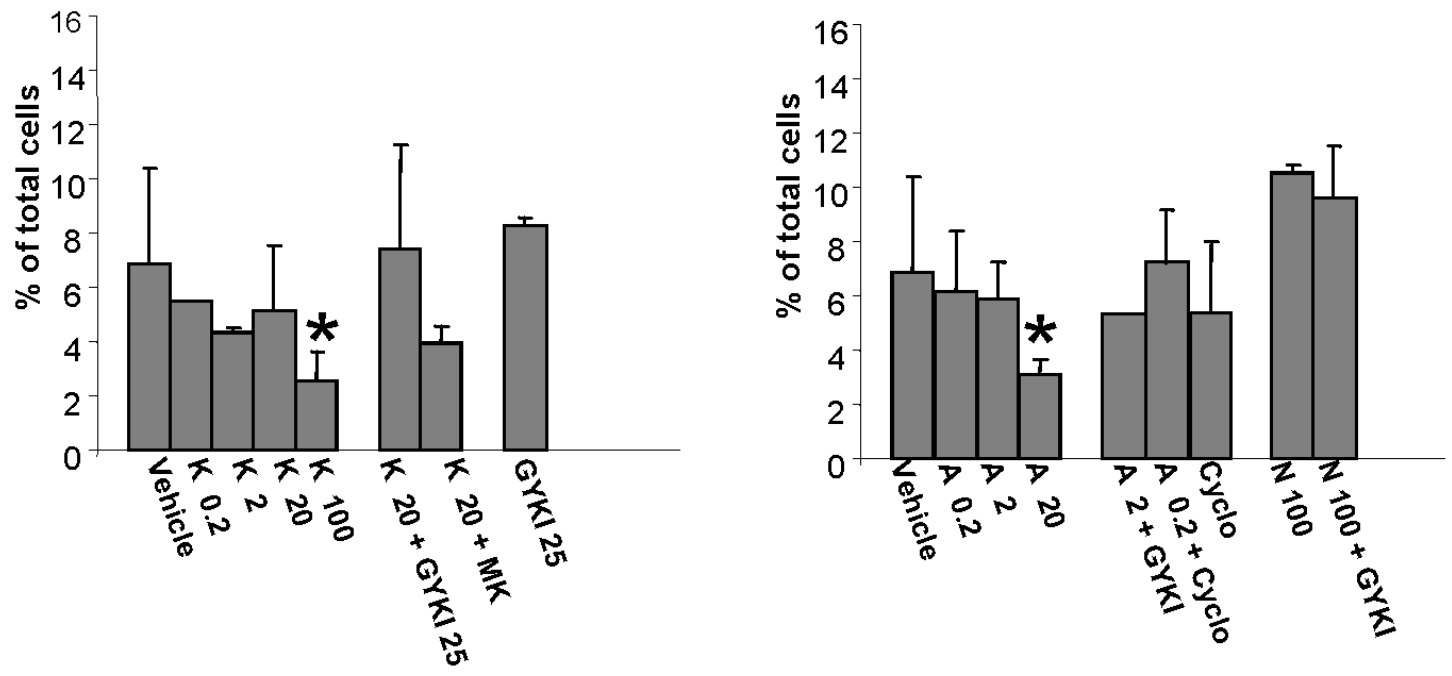

Fig 2. AMPA \& NMDA receptors increase survival of granule neurons in cerebellar cultures A,B Survival of cerebellar neurons was increased by treatments for 5 days with increasing doses of kainate $(K, \mathbf{A})$ and $\operatorname{AMPA}(A, \mathbf{B})$. Combination of these treatments with the selective AMPA receptor antagonist GYKI52466 (GYKI, $25 \mu \mathrm{M})$ completely blocked this action. In contrast, blockade with the NMDA receptor antagonist MK801 $(M K, 10 \mu \mathrm{M})$ failed to reverse kainate action. In B is also shown that GYKI52466 $(25 \mu \mathrm{M})$ failed to reverse the reported facilitation of survival with $\operatorname{NMDA}(N, 100 \mu \mathrm{M})$ treatment. Cyclothiazide $(C y c l o, 100 \mu \mathrm{M})$ failed to enhance the action of AMPA.

C,D Survival of eGFP positive neurons expressed as \% of total number of cells in each field analyzed. Although both treatments increased the total number of neurons and therefore the 
absolute number of eGFP labeled GABAergic interneurons, the percent of these neurons was not increased by treatments with increasing doses of both kainate (A) and AMPA (B) in contrast to treatments with NMDA. Data derive from at least 6 coverslips from four distinct cultures and are expressed as mean $\pm \mathrm{SD}$. * significant to control, $p<0.01$. + significant to K20+GYKI, $p<0.01$. 
A

area terminals Kainate

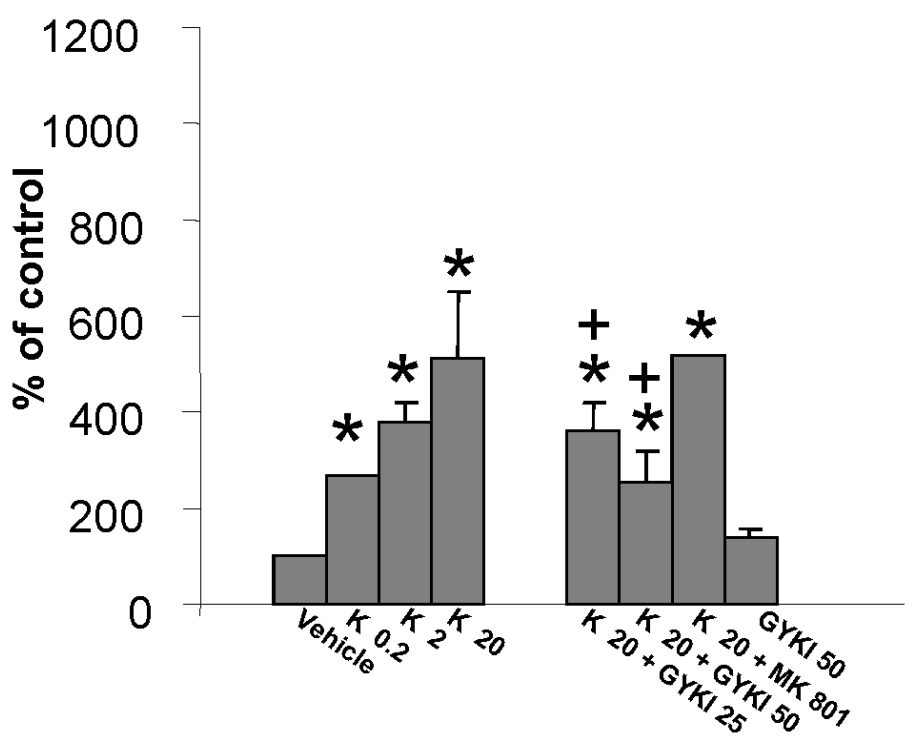

area terminals AMPA

B

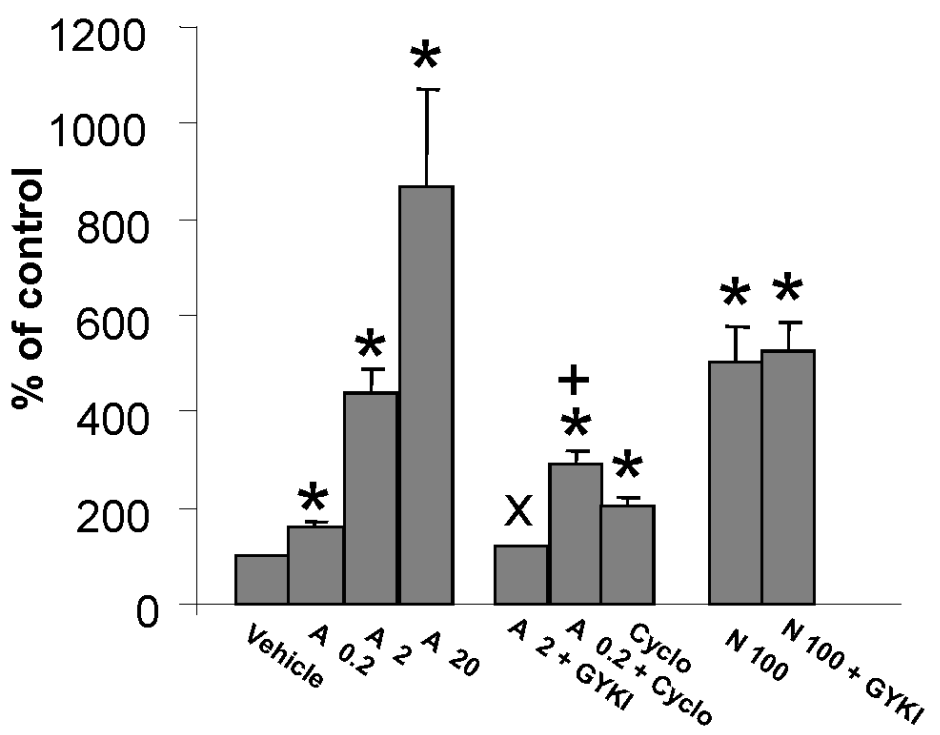

Fig3. Kainate and AMPA enlarge GABAergic terminals

Summary results on the analysis of eGFP labeled varicosities in axons of cerebellar GABAergic interneurons grown in distinct culture conditions.

A: The percentage increase in the area of the varicosities induced by $0.2,2$, and $20 \mu \mathrm{M}$ Kainate is compared to the increase obtained in the presence of kainate $(K, 20 \mu \mathrm{M})$ together with GYKI52466 (GYKI, $25 \mu \mathrm{M}$ or $50 \mu \mathrm{M})$ or MK801 $(M K, 10 \mu \mathrm{M})$. No change in terminal size was seen with GYKI52466 (GYKI, $50 \mu \mathrm{M})$ alone. The area of varicosities in the vehicle group was $0.75 \pm 0.18 \mu \mathrm{m}^{2}$. * significant to vehicle, $p<0.01$. + significant to $\mathrm{K} 20, p<0.01$.

B: The steep increase in the area of varicosities caused by increasing doses of AMPA ( $A, 0.2$, 2 and $10 \mu \mathrm{M})$ is compared to that of NMDA $(N, 100 \mu \mathrm{M})$. GYKI52466 blocked AMPA but 
not NMDA-induced increase in the size of the varicosities. In addition it is shown the effect on varicosity enlargement of cyclothiazide $(C y c l o, 100 \mu \mathrm{M})$ a drug that selectively potentiates the action of flip variants of AMPA receptors. Data derive from at least 30 segments in each experimental group from 6 separate cultures and are expressed as mean $\pm \mathrm{SD}$. * significant to vehicle, $p<0.01$. + significant to A $0.2, p<0.01 . \times$ significant to A $2, p<0.01$. 
A

CGCs
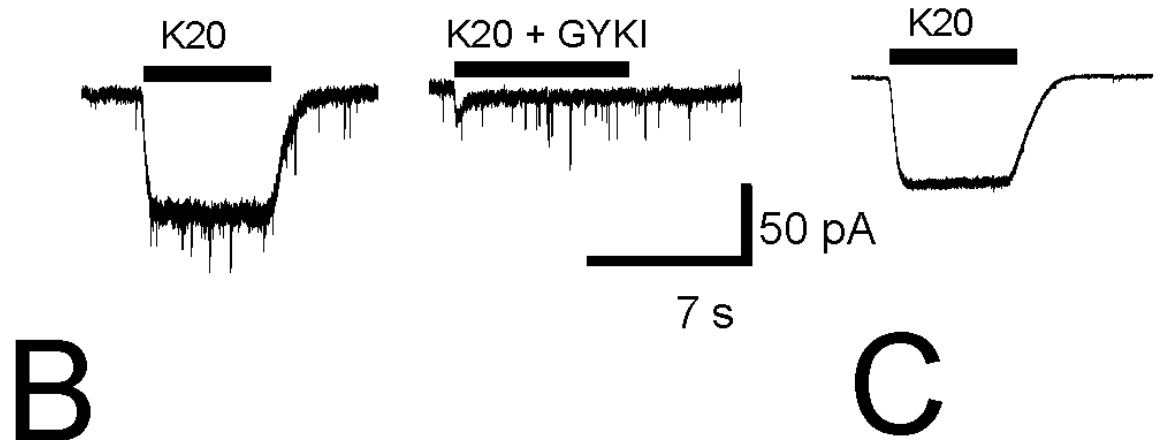

$7 \mathrm{~s}$
Interneurons

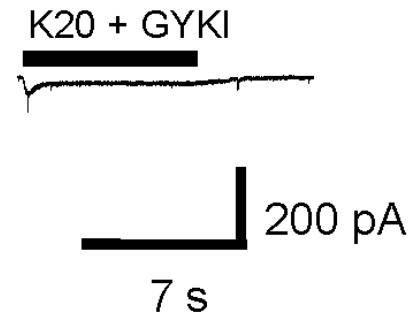

CGCs

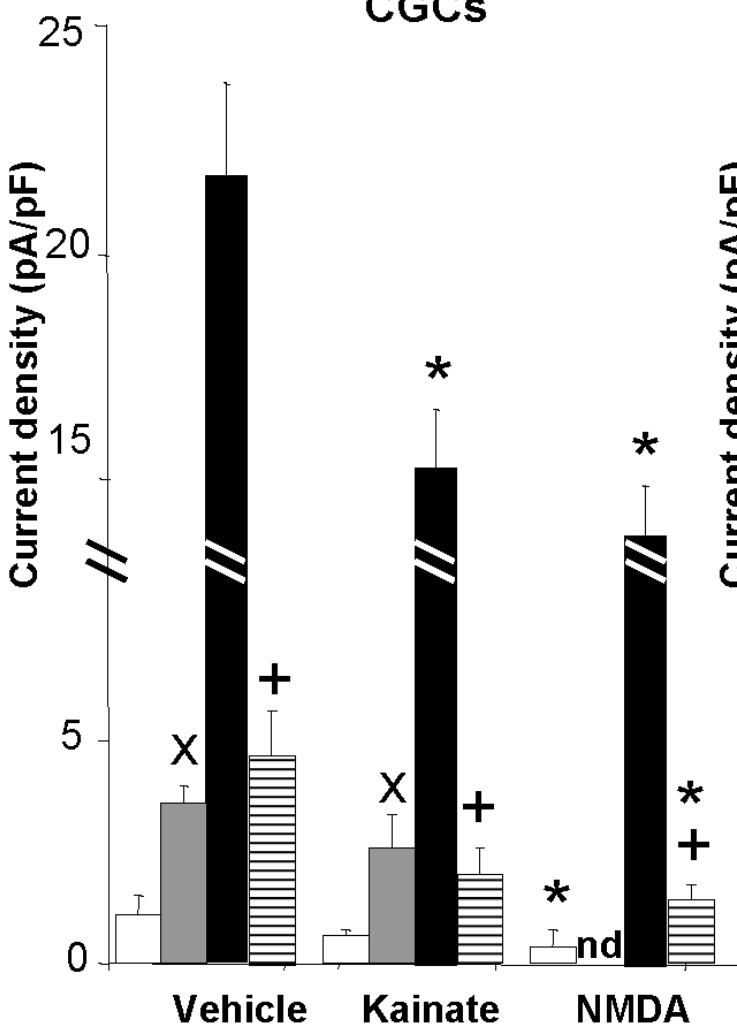

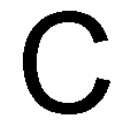

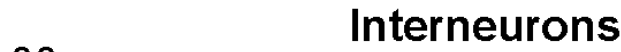

80

Interneurons nd NMDA

Fig 4. Whole cell current elicited by kainate in CGCs and interneurons

Effect of direct application of kainate to cerebellar granule neurons and interneurons at DIV 7-8.

A: Comparison of representative whole cell current records from a granule cell (left) and an interneuron (right) at DIV7, voltage clamped at $-60 \mathrm{mV}$. Horizontal bars correspond to the acute application of kainate $(20 \mu \mathrm{M}, \mathrm{K} 20)$ alone or in combination with GYKI (50 $\mu \mathrm{M}, \mathrm{K} 20$ $+\mathrm{GYKI})$. The average whole cell current density obtained with applications of $20 \mu \mathrm{M}$ kainate in cerebellar granule neurons $(\mathbf{B})$ or interneurons $(\mathbf{C})$ is reported for cells in control conditions or cells treated for 5 days with kainate $(20 \mu \mathrm{M})$ or NMDA $(100 \mu \mathrm{M})$. Also included is a comparison of whole cell current density obtained with $2 \mu \mathrm{M}$ kainate $(\mathrm{K} 2), 2 \mu \mathrm{M}$ kainate +20 
$\mu \mathrm{M}$ Con $\mathrm{A}(\mathrm{K} 2+\mathrm{conA})$ and $20 \mu \mathrm{M}$ kainate $+50 \mu \mathrm{M}$ GYKI $52466(\mathrm{~K} 20+\mathrm{GYKI})$ in cerebellar granule neurons $(\mathbf{B})$ or interneurons $(\mathbf{C})$ in control conditions or treated for 5 days with kainate $(20 \mu \mathrm{M})$ or NMDA $(100 \mu \mathrm{M})$. Data derive from at least 15 granule neurons and 16 interneurons in 5 distinct sets of cultures at DIV7-8 for vehicle and kainate treatment and from 6 granule neurons and 5 interneurons for NMDA treatments. * significant to vehicle, $p<0.01 .+$ significant to $\mathrm{K} 20, p<0.01 \times$ significant to $\mathrm{K} 2$ application, $p<0.01$. 


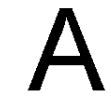

\section{CGCs}

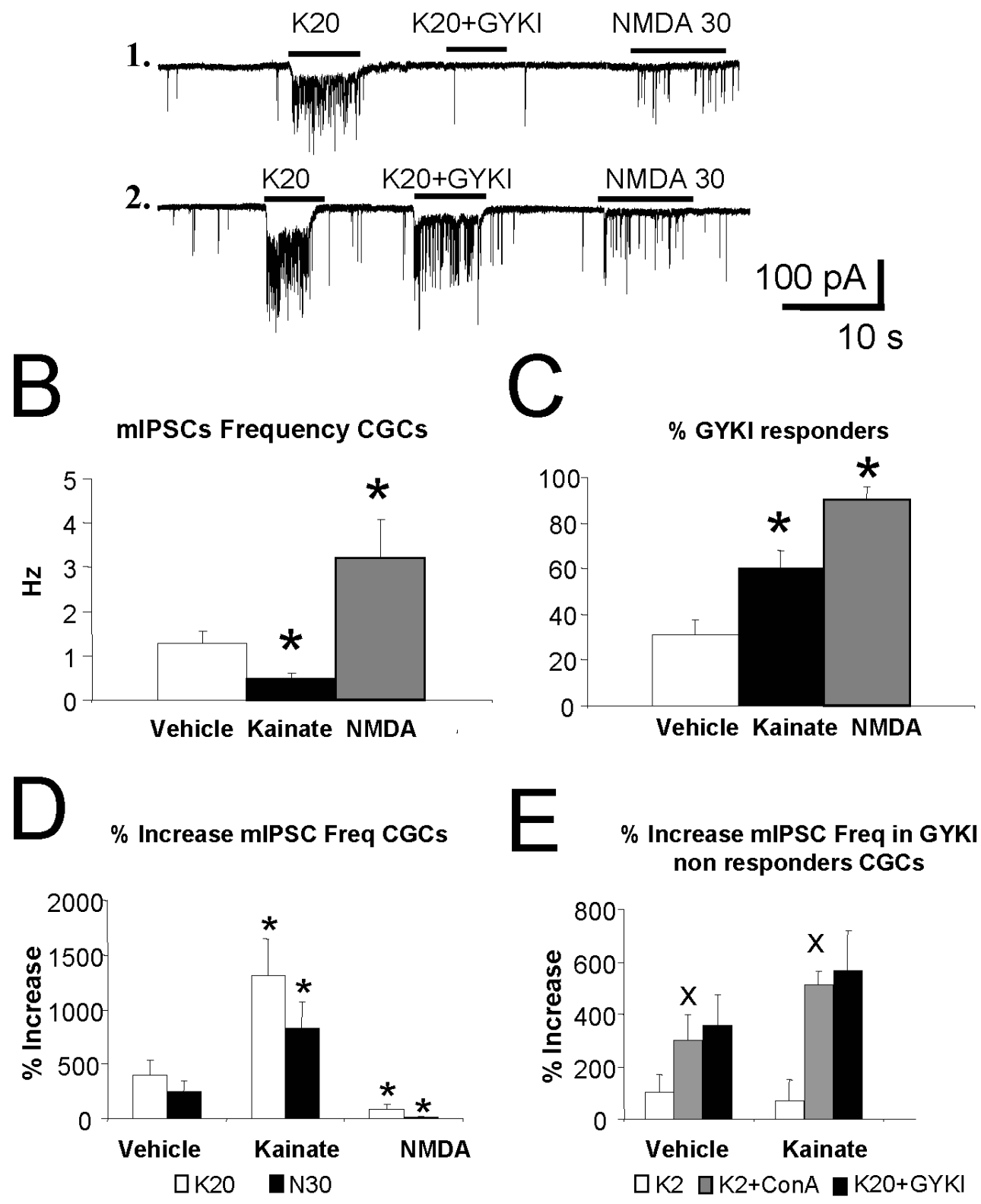

Fig 5. increase of mIPSCs by kainate is altered by chronic treatments with kainate and NMDA Effect of chronic and acute application of kainate and NMDA on GABAergic mIPSCs recorded from cerebellar granule cells at DIV 7-8.

A. Representative miniature inhibitory postsynaptic currents (mIPSCs) records from cerebellar granule neurons at DIV 7 grown in vehicle, control conditions. Horizontal bar corresponds to the acute application of kainate $(K, 20 \mu \mathrm{M}$ K20) alone or together with GYKI52466 (50 $\mu \mathrm{M}$, $\mathrm{K} 20+\mathrm{GYKI})$. The effect of NMDA $(N M D A, 30 \mu \mathrm{M})$ is also illustrated. Recordings from cells $1 \& 2$ differ dramatically in the action of GYKI52466 suggesting the presence of presynaptic kainate receptors in cell 2. 
B. A comparison of the average mIPSCs frequency in granule neurons at DIV7 grown in vehicle or chronically treated with kainate $(20 \mu \mathrm{M})$ or NMDA $(100 \mu \mathrm{M})$ for 5 days. ${ }^{*} \mathrm{p}<0.01$ compared to vehicle.

C. A comparison of the percent of cells that did not display increase in mIPSC frequency with coapplication of $20 \mu \mathrm{M}$ kainate and $50 \mu \mathrm{M}$ GYIK52466 (\%GYKI) in granule neurons at DIV7 grown in control conditions or chronically treated with kainate $(20 \mu \mathrm{M})$ or NMDA $(100 \mu \mathrm{M})$ for 5 days. Data derive from 15 granule neurons in 5 different cultures and averaged across distinct cultures $* \mathrm{p}<0.01$ compared to vehicle.

D. Comparison of the \% increase of mIPSC frequency by acute applications of $20 \mu \mathrm{M}$ kainate $(K 20)$ with NMDA $(N, 30 \mu \mathrm{M})$ (Left panel) in control cells as compared to cells chronically treated with kainate $(20 \mu \mathrm{M})$ or NMDA $(100 \mu \mathrm{M})$ for 5 days. * significant to vehicle treated cells, $p<0.01$. Data from at least 15 granule neurons in 5 distinct sets of cultures at DIV7-8 for control and kainate treatment and from 6 granule neurons and 7 interneurons for NMDA treatments.

E. Comparison of the \% increase of mIPSC frequency by acute applications of $2 \mu \mathrm{M}$ kainate with $20 \mu \mathrm{M}$ kainate $+50 \mu \mathrm{M}$ GYKI52466 $(K 20+G Y K I$, $)$ or $2 \mu \mathrm{M}$ kainate after pretreatment with ConA $20 \mu \mathrm{M}(K 2+\operatorname{con} A)$ in cells that responded with mIPSCs frequency increase even when kainate and GYKI52466 were combined (GYKI non responder cells). Vehicle treated cultures were compared to cultures chronically treated with kainate $(20 \mu \mathrm{M})$ for 5 days. $\times$ significant to K2 application, $p<0.01$. Data derives from at least 6 cells in two separate cultures 


\section{A}

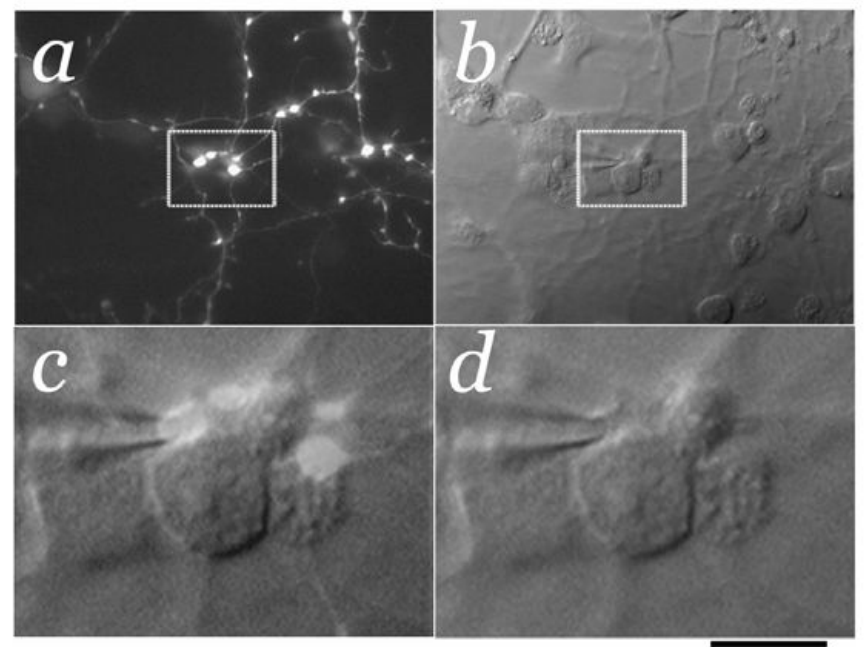

Terminal recordings

Direct application on Terminals
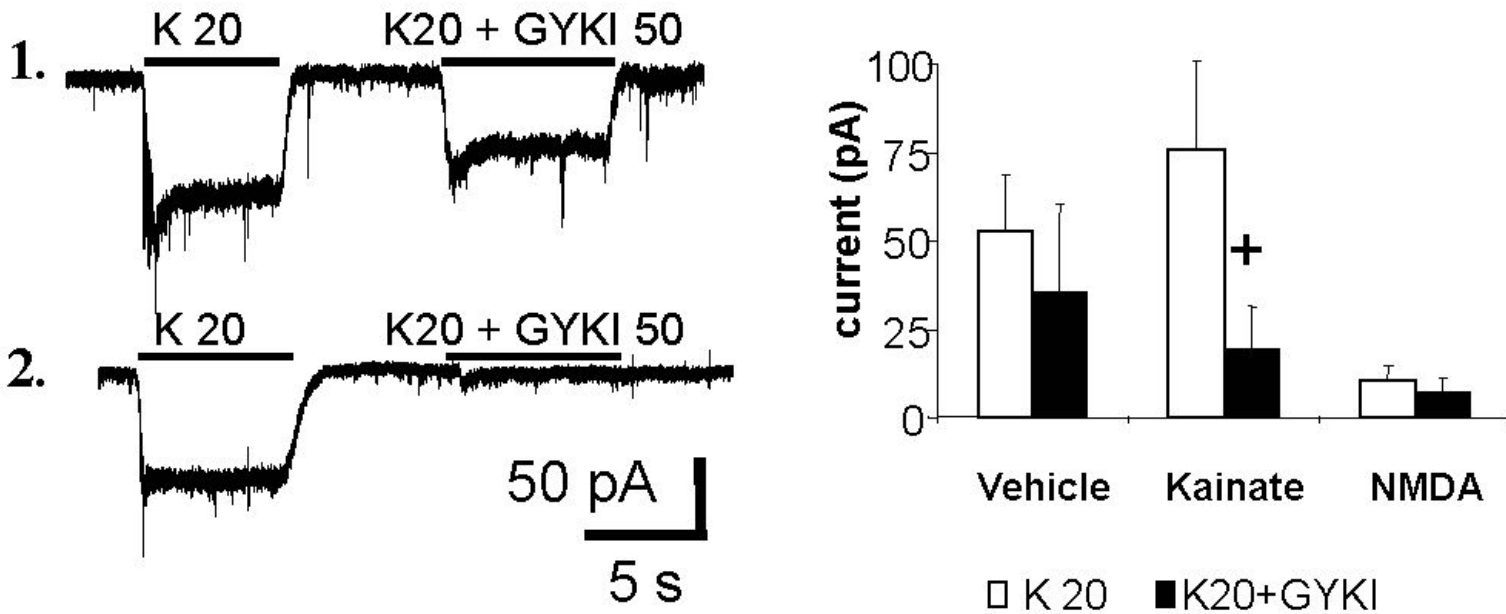

Fig 6. Kainate current recordings from presynaptic terminals

A. Microphotographs of cerebellar neurons at DIV8 in a kainate treated culture. Panel $\boldsymbol{a}$ shows GFP positive axons with large varicosities. The same field is shown to the right with DICNomarski optics (panel $\boldsymbol{b}$ ). White box inserts are magnified below showing a varicosity (GFP/ DIC-Nomarski, panel $\boldsymbol{c}$ ) in close proximity to the cell body of a granule neuron. The tip of a patch pipette touching the varicosity is shown in panel $\mathrm{d}$. Calibration bar $30 \mu \mathrm{m}(\boldsymbol{a}, \boldsymbol{b})$ and 7 $\mu \mathrm{m}(\boldsymbol{c}, \boldsymbol{d})$.

B. Voltage-clamp current recording from two distinct GFP labeled varicosities in kainate treated cells illustrating kainate-elicited current and the variability of antagonism by the AMPA receptor selective antagonist GYKI52466. 
C. Summary of whole-terminal current activated by kainate $(K)$ at $20 \mu \mathrm{M}$, or kainate $20 \mu \mathrm{M}+$ GYKI52466 $(K 20+G Y K I, 50 \mu \mathrm{M})$ in control cells as compared to cells chronically treated with kainate $(20 \mu \mathrm{M})$ or NMDA $(100 \mu \mathrm{M})$ for 5 days. $+\mathrm{p}<0.05$ compared to kainate $(K)$ at $20 \mu \mathrm{M}$. Data derive from $>10$ terminals in 2 distinct sets of cultures at DIV7-8 for control and kainate treatment and from 5 terminals for NMDA treatments. 